\title{
Recurrent Oral Cavity Mucoepidermoid
} Carcinoma

National Cancer Institute

\section{Source}

National Cancer Institute. Recurrent Oral Cavity Mucoepidermoid Carcinoma. NCI

Thesaurus. Code C8215.

The reemergence of mucoepidermoid carcinoma in the oral cavity after a period of remission. 